
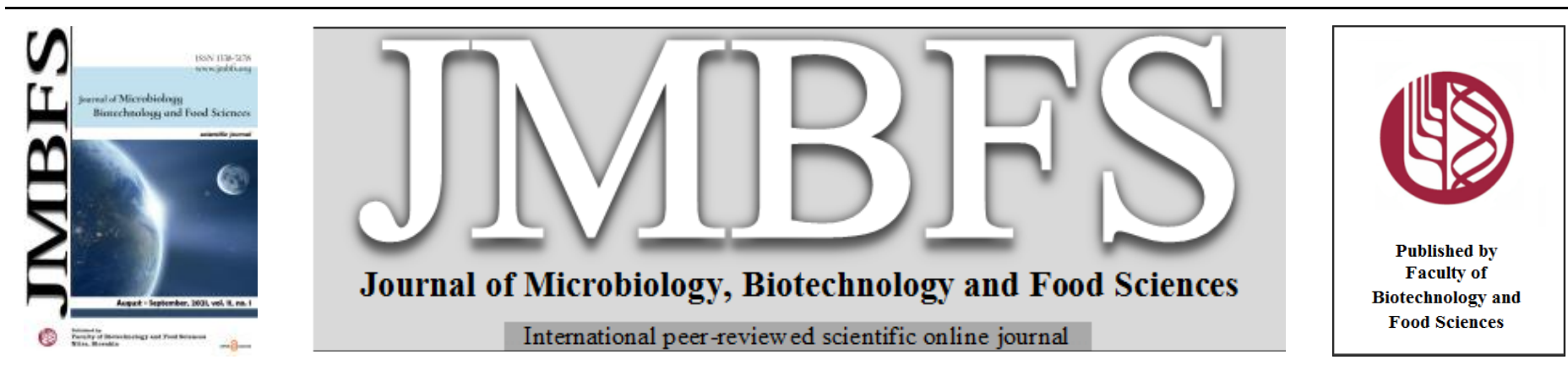

\title{
BURKHOLDERIA CEPACIA BAM-12 ISOLATED FROM MUNGBEAN FIELD IN RAJASTHAN AUGMENTS PLANT GROWTH IN AGRICULTURAL FIELD SOIL OF GUJARAT, INDIA
}

\author{
Tejal Popat ${ }^{l}$, Anamika Jha ${ }^{1,2 *}$
}

$\operatorname{Address(es):~}$

${ }^{1}$ Ashok and Rita Patel Institute of integrated Study and Research in Biotechnology and Allied Sciences (CVM University), New Vallabh Vidyanagar, Anand-388121, Gujarat, India.

${ }^{1}$ Department of Biological Sciences, P D Patel Institute of Applied Sciences, Charotar University of Science and Technology, Changa, Anand-388421, Gujarat, India.

*Corresponding author: anamikajha2203@gmail.com

\section{ARTICLE INFO}

Received 5. 6. 2020

Revised 4. 3. 2021

Accepted 10. 3. 2021

Published 1. 8. 2021

Regular article OPEN $\partial_{\text {ACCESS }}$

\begin{abstract}
Application of exotic bacterial strains as biofertilizer has always posed a constraint in the success of biofertilizer technology. Only a limited number of biofertilizers with applicability in a wide range of soil conditions is available in the market. Pseudomonas cepacia BAM-12 (MTCC No. 7100) (now known as Burkholderia cepacia), an isolate from the mungbean rhizosphere of the agricultural field of Rajasthan has shown remarkable plant growth promotion in Gujarat agricultural field soil. B. cepacia was found to increase the overall growth of 3 agriculturally important plants widely grown in Gujarat region, viz., mungbean, maize and rice. Increased plant growth was assessed on the basis of increased leaf number and area, biomass, chlorophyll content, profuse adventitious root branching, increased nodulation (in mungbean only), high available $\mathrm{P}$ in soil and overall plant growth in B. cepacia treated plants. Vital factor towards increased plant growth was the amount of IAA secreted by the organism (i.e. $2.65 \mathrm{mg}$ IAA/100 $\mathrm{ml}$ of the culture filtrate) which is reasonably high in comparison to earlier reports available. Furthermore, PSB has also demonstrated bioremediation potential against harmful heavy metals such as copper, lead, nickel and arsenic by tolerating upto $25 \mathrm{mM}$ indicating it's prospective in remediating heavy metal contaminated agricultural fields.
\end{abstract}

Keywords: Biofertilizer; phosphate solubilizing bacteria; IAA; Burkholderia cepacia catecholate, mungbean, siderophore

\section{INTRODUCTION}

Agricultural land gets impoverished after long term cultivation, if not supplemented properly with nutrient inputs. To supplement the soil nutrient content under conventional farming systems, we need to apply high doses of agrochemicals. But during the last couple of decades chemical fertilizers have given a negative impact on the environment which in turn pollutes the ecosystem. Therefore, in order to make agriculture sustainable, it is necessary to implement a balanced and responsible use of organic agriculture (Slama et al., 2019). The principles of biofertilizers outline the similar concept where the soil health and biodiversity is built up to sustain the plant growth in longer term (Mehrvarz, 2008; Jha et al., 2011). The application of environmental friendly practices is promoted by voluntary certification schemes (e.g., Global GAP or organic farming schemes) as well as by legally binding regulations (e.g., the EU Directive 2009/128) aiming at the implementation of sustainable pest management practices).

Biofertilizers help to build up the soil micro-flora and thereby the soil health. The existence of a microorganism increases the growth of plants by replacing soil nutrients (e.g., by biological $\mathrm{N}_{2}$ fixation, $\mathrm{BNF}$ ) or making nutrients more available (e.g., by solubilization of phosphates) or increasing plant access to nutrients (e.g., by increasing root surface area) or releasing the plant growth regulating substances such as IAA, Gibberellins, Cytokinins etc. (Vessey, 2003) One such group of bacteria that has been extensively investigated is plant growth promoting rhizobacteria (PGPR). PGPR are root colonizing bacteria that not only acquire benefit from the nutrients secreted by the plant root but also beneficially influence the plant in direct or indirect way like controlling phytopathogens (Parikh \& Jha, 2012), resulting in stimulation of its growth (Reddy et al., 2002).

Pseudomonads are the most prevalent group among bacteria which dominate in the plant rhizosphere due to its high rhizosphere competence and therefore, the best colonizers (Dekkers, 1992). Several Pseudomonads have demonstrated their capability in promoting the overall growth of several plant species (Nezarat $\&$ Gholami, 2009; Shrivastava \& Shalini, 2009; Jha et al., 2012). Pseudomonas cepacia promotes growth of plant mainly by solubilization of phosphate present in the soil by bringing about changes in rhizospheric soil $\mathrm{pH}$ and also by chelating substances which lead to solubilization of phosphates (Jha et al., 2012, 2013). In addition to phosphate solubilization, production of plant growth regulating substances of the auxin type contributes to their stimulating effects on plant growth (Dubey \& Maheshwari, 2003).

Intensification of energy-related and other industrial processes associated with production of wastes and by-products rich in heavy metals and other xenobiotic compounds has led to serious soil contamination of many industrial sites. The resultant accumulations of the various organic chemicals in the environment particularly in soil, are of significant concern because of their toxicity, including their carcinogenicity, and also because of their potential to bioaccumulate in living systems (Jain et al., 2014). Thus, the intracellular concentration of heavymetal ions has to be strongly controlled. Studies have shown that microorganisms are able to accumulate metal ions via processes such as transportation across the cell membrane (Jain et al., 2012), biosorption onto cell wall, entrapment in extracellular capsule, precipitation, oxidation-reduction reaction and biosorption to extracellular polysaccharide (Nies, 1999). Again Pseudomonads have received a great attention in this area also.

Although there are several marketed biofertilizers but, only limited numbers having applicability in variable soil conditions are available. In the past also there have been several reports where biofertilizer showed remarkable results in one state/country but was ineffective in another (Phospho-bacteria was successful in USSR but failed in other countries). In addition, another constraint associated with the wide application of biofertilizers is their crop specificity. Also, separate microbial formulations are required for different applications such as fertilization, bioremediation and many more. Therefore, scientists are in search of potential microbes exhibiting multiple properties that can be effectively applied to different crops and soil types in variable environmental conditions to promote the overall plant growth.

Realizing the needs in light of the foregoing discussion, an efficient phosphate solubilizing strain, Burkholderia cepacia BAM-12 (MTCC No. 7100, Genbank Accession No.1202914), an isolate from mung bean rhizosphere of the agricultural field of Rajasthan (Anamika et al., 2007) was selected for the present study. The in vitro and in Planta plant growth promoting and biocontrol activities of BAM-12 were tested in 3 agriculturally important crop plants, viz., maize, mung bean and rice grown in Gujarat agricultural field soil. Further, the 
heavy metal tolerance of the strain was also investigated to add more objectives to use them as bio-inoculant in heavy metal contaminated sites.

\section{MATERIALS AND METHODS}

\section{In vitro experimentation demonstrating Plant growth promoting activity}

Qualitative Phosphate solubilization assay: The ability of B. cepacia (BAM-12) to solubilize phosphate was assessed using Pikovskaya's agar medium (containing 1\% methyl red). Bacterial culture was spotted in the centre of the plate and incubated at $30^{\circ} \mathrm{C}$ for 10 days. The solubilization index was calculated by measuring the zone of clearance and change of media colour from yellow to pink in the solubilization zone around the bacterial colony applying the following formula (Kumar \& Narula, 1999):

Solubilization index $=\mathrm{A} / \mathrm{B}$

$\mathrm{A}=$ diameter (colony + halozone)

$\mathrm{B}=$ colony diameter

Quantitative Phosphate solubilization assay: Quantitative determination of $\mathrm{P}$ solubilization by the isolate BAM-12 in broth was carried out in $100 \mathrm{ml}$ of Pikovskaya's broth (PB) medium. Composition of PB medium used is as follows (g/l of distilled water): dextrose, $10 ;\left(\mathrm{NH}_{4}\right)_{2} \mathrm{SO}_{4}, 0.5 ; \mathrm{MgSO}_{4} .7 \mathrm{H}_{2} \mathrm{O}, 0.1 ; \mathrm{KCl}, 0.2$ Yeast extract, 0.5; $\mathrm{MnSO}_{4} .7 \mathrm{H}_{2} \mathrm{O}, 0.002$; and $\mathrm{FeSO}_{4} 7 \mathrm{H}_{2} \mathrm{O}, 0.002$. Tricalcium Phosphate was added @ $0.1 \%$ to all the flasks separately as a source of insoluble phosphate. The media were then inoculated with $0.2 \mathrm{ml}$ of respective bacteria culture (OD of 0.25 at $590 \mathrm{~nm}$ ). Autoclaved PB medium without inoculation was considered as a control. The flasks were incubated for 5 days at $30 \pm 2^{\circ} \mathrm{C}$ on an orbital incubator shaker at $130 \mathrm{rpm}$ (Jha et al., 2012). Culture samples were harvested aseptically after every $24 \mathrm{hrs}$ and water-soluble phosphate in the supernatant was determined upto 5 days according to the method of Olsen and Sommers (1982). Change in $\mathrm{pH}$ of culture broth was also recorded after every sampling.

IAA production by $B$. cepacia: Bacterial culture was tested to produce Indole Acetic Acid (IAA, an auxin) under culture conditions by growing the isolate in nutrient broth containing $0.5 \%$ glucose and $500 \mu \mathrm{g} / \mathrm{ml}$ tryptophan and incubated at $30 \pm 2^{\circ} \mathrm{C}$ for 6 days. Then, $5 \mathrm{ml}$ culture was taken and centrifuged at $10,000 \mathrm{rpm}$ for $15 \mathrm{~min}$. Supernatant $(2 \mathrm{ml})$ was taken and $100 \mu \mathrm{l}$ of $10 \mathrm{mM} \mathrm{O}$-phosphoric acid and $4 \mathrm{ml}$ reagent $\left(1 \mathrm{ml} 0.5 \mathrm{M} \mathrm{FeCl}{ }_{3}+50 \mathrm{ml} 35 \% \mathrm{HClO}_{4}\right)$ were added to it and incubated at room temperature for $25 \mathrm{~min}$. Absorbance was read at $530 \mathrm{~nm}$ against blank (Bric et al., 1991).

Antibiotic sensitivity test: Antibiotic sensitivity test of B. cepacia BAM-12 was performed using disc impregnated with antibiotics of different known concentrations (Hi-media, Mumbai, India). Six noted antibiotics, namely Nalidixic acid (30 mcg), Tetracycline (30 mcg), Penicillin (2 mcg), Erythromycin (15 mcg), Streptomycin (10 mcg) and Ampicillin were used. The discs were placed in circular manner over the surface of seeded BAM-12 strain in nutrient agar plates. The plates were incubated at $30 \pm 2^{\circ} \mathrm{C}$ for $24 \mathrm{hrs}$

\section{Biocontrol activities}

Chitinase production: Chitin agar plates were inoculated with BAM-12 and incubated at $30^{\circ} \mathrm{C}$ for 3-4 days. $1 \%$ Congo red solution was poured onto the plates. The plates were incubated for $30 \mathrm{~min}$ at room temperature then they were washed with $1 \mathrm{M} \mathrm{NaCl}$ solution. Clear zones around the colonies on a red background were taken as the evidence for the chitinase activity.

Lipase production: Strain was tested for production of extracellular lipase enzyme by conducting the assay on tributyrin agar plates. Organism was spo inoculated on tributyrin agar plate and incubated under standard growth conditions for 4 days. A clear halo around the colony was indicating lipase production.

Siderophore production: Siderophore production by B. cepacia BAM-12 was tested using Chrome-azurol S (CAS) assay medium (Schwyn \& Neliands, 1987). Organism was spot inoculated on a CAS medium plate and observed for production of yellow-orange halo around it. The diameter of the halo was observed after every $24 \mathrm{hrs}$ till 10 days to calculate the siderophore production efficiency.

Testing for production of Catecholate type Siderophore by Arnow's Assay: $B$ cepacia culture was grown in Ashby's medium for $48 \mathrm{hrs}$. One $\mathrm{ml}$ of $0.5 \mathrm{M} \mathrm{HCl}$, $1 \mathrm{ml}$ Nitrite molybdate reagent (prepared in sterile distilled water) was added to 1 $\mathrm{ml}$ of cell-free culture supernatant. Uninoculated medium served as a control. After 5 min $1 \mathrm{~N} \mathrm{NaOH}$ was added and observed for development of pink color whose intensity was measured at $500 \mathrm{~nm}$ using 2, 3-DHBA (Di-hydrobenzoic acid) as a standard (Arnow, 1937)
Testing for production of Hydroxamate type Siderophore by Atkin's Assay: Production of Hydroxamate-type of siderophores was detected and estimated in 1 $\mathrm{ml}$ of $P$. cepacia BAM-12 culture supernatant by ferric-perchlorate assay (Atkin et al., 1970)

\section{HCN Production}

Method 1(Colorimetric method): Culture was centrifuged at $7000 \mathrm{rpm}$ for 15 min. at $4^{\circ} \mathrm{C}$ and supernatant was passed from $0.2 \mu$ filter and $\mathrm{O}$-phosphoric acic was added $(2 \mathrm{ml})$ and was observed for development of pink color. The absorbance was read at $530 \mathrm{~nm}$ against blank.

Method 2 (Inverted plate technique): In this technique BAM-12 strain was grown in $10 \mathrm{ml}$ of Luria-Bertani (LB) medium after incubation at $30^{\circ} \mathrm{C}$. A loopful of grown bacterial culture was streaked on the NA plate. Fungal strains were grown on potato dextrose agar (PDA) plates. An agar block of $5 \times 5 \mathrm{~mm}^{2}$ was cut from the periphery of the plate containing growing mycelium of the test fungi and was placed in the center of a fresh PDA plate. The BAM-12 streaked bacterial plate was inverted on the fungal culture plate and plates were sealed with cellophane. A control plate was also prepared which contained the test pathogen only. The plates were incubated at $30 \pm 2^{\circ} \mathrm{C}$ and were observed after 3 days.

In vitro Antifungal activity of $B$. cepacia against Macrophomina phaseolina: 'Antagonism' is of common occurrence among microorganisms inhabiting the soils. Antagonistic activity of the strain BAM-12 was checked against an important devastating fungal phytopathogen viz., Macrophomina phaseolina (MTCC No. 166). Following 3 methods were employed to check the antifungal potential of B. cepacia against $M$. phaseolina.

Dual culture plate technique: Bacterial strain was grown in $10 \mathrm{ml}$ of LB medium after incubation at $30^{\circ} \mathrm{C}$. Fungal strain was grown on PDA plates. An agar block of $0.5 \times 0.5 \mathrm{~cm}^{2}$ was cut from the periphery of the plate containing growing mycelium of the test fungi and was placed in the center of a fresh PDA plate. Different amounts $(10 \mu \mathrm{l}, 25 \mu \mathrm{l}$ and $50 \mu \mathrm{l})$ of mid-log phase BAM-12 bacterial culture were added in the wells equidistant from the center. A control plate was also prepared which contained the test pathogen only and the wells were filled with distilled water. The plates were incubated at $30 \pm 2^{\circ} \mathrm{C}$ and were observed after 7 days. Same procedure was repeated using a Minimal Essential Medium (MEM) to test the activity in deficient conditions.

Antifungal activity in broth: Fresh culture filtrate $(10,20,30 \mathrm{ml})$ of B. cepacia was transferred separately in $250 \mathrm{ml}$ conical flask containing $90,80,70 \mathrm{ml}$ of yeast extract mannitol (YEM) broth (containing 2\% sucrose) to check its antifungal potential. Actively growing mycelial discs from 5 day old culture of M. phaseolina were also transferred into each flask. The flasks were incubated at ambient temperature for 10 days at $120 \mathrm{rpm}$ shaking. Flasks containing only mycelial discs in the medium served as control. After 10 days of incubation, fresh mycelial mat was harvested and dried at $85^{\circ} \mathrm{C}$ for $24 \mathrm{hrs}$ to constant weight for obtaining fungal dry weight. Microscopic analysis of cultures after 10 days incubation was also performed to observe the effect of bacterial culture filtrate on growth and morphology of fungal mycelium.

In vitro spore germination: Culture suspension of $B$. cepacia was prepared by inoculating it in LB medium and growing for 2 days to obtain sufficient cell density. Bacterial cells were pelleted to obtain the culture filtrate. One drop from culture filtrate was placed on a grease-free slide. Fungal spores were picked from 7-10 days old culture with sterilized inoculation needles and mixed with bacterial culture filtrate. The slides were placed in moist chambers made by placing two sterile filter papers each on lids and base of the petriplates. The slides with spores were then incubated at $25 \pm 2^{\circ} \mathrm{C}$ for $24 \mathrm{hrs}$. Spore germination was observed under a binocular microscope after staining with cotton blue. Spores mixed in sterile distilled water only served as control. All experiments were conducted in triplicates.

\section{In planta studies}

\section{Soil measurements}

Soil testing: The experiment was conducted in a typical sandy clay loam soil and following parameters were analyzed before start of the experiment:

Soil pH, Moisture content and Available P: The method of Allen (1989) was followed to determine the soil $\mathrm{pH}$ using $0.01 \mathrm{M} \mathrm{CaCl}_{2} \cdot 2 \mathrm{H}_{2} \mathrm{O}$ solution. $\mathrm{pH}$ meter was calibrated with standard buffers of $\mathrm{pH} 4.0,7.0$ and 9.2 prior to actua measurements.

To determine the soil moisture, the technique outlined by Piper (1950) was used The soil moisture in percent was calculated by using following formula: Moisture content $(\%)=\underline{\text { Initial weight }- \text { Final weight }} \times 100$ Initial weigh 
To determine the available $\mathrm{P}$ concentration (determined before sowing and after 30 days of seed sowing), the samples were first extracted with $0.5 \mathrm{M} \mathrm{NaHCO}$ (Olsen's reagent) and then available $\mathrm{P}$ was determined according to Olsen \& Sommers (1982).

Microbial count: The microbial count was also determined before and after 30 days of sowing. The rhizoplane and rhizosphere soil were separated by gentle tapping and composite samples were prepared. The soil samples were then air dried at room temperature and enumeration of PSB was determined by the dilution plating technique.

\section{Bioinoculant application}

Three plants, viz., rice, mung and maize were chosen for the investigation. The experiment was set in a Randomized Block Design (RBD) and 4 replicates were taken for each set of experiments. The treatments included:

(i) Uninoculated control and (ii) Treated: Seeds treated with the culture of $B$ cepacia.

Same treatments were taken for all the 3 plants, viz., rice, mung and maize. The experiment was carried out in open for 30 days during spring season (FebruaryMarch) following normal agronomical practices described for the cultivation of three crop species. Watering of the plants was carried out on alternate days.

Preparation of inoculum: A loopful of the fresh bacterial culture was inoculated in $50 \mathrm{ml}$ of $\mathrm{PB}$ and incubated at $30 \pm 2^{\circ} \mathrm{C}$ for 4 days in an incubator shaker.

Seed pelleting and sowing: 4-day old cultures having bacterial cell density of $1.6 \times 10^{8} \mathrm{cfu} / \mathrm{ml}$ were mixed with jaggery solution separately. Mung bean, maize and rice seeds were surface sterilized by immersing them in $0.1 \%$ of $\mathrm{HgCl}_{2}$ solution for $3 \mathrm{~min}$. The seeds were then rinsed with sterile d.w for 3 times and then blotted on a sterile filter paper, dried and pelletized in the bacterial culture. These seeds were left for air-dying. Aseptic measures were followed during the entire process and performed in a laminar air flow. Air dried seeds were sown immediately at a depth of $2 \mathrm{~cm}$ in $1 \mathrm{Kg}$ plastic pots filled with $1 \mathrm{Kg}$ sterilized soil.

To assess the plant growth, following parameters were studied:

Percent germination of seeds (after 5 days of sowing), Shoot and root length (after 15 and 30 days of sowing); Shoot dry weight, root dry weight, leaf area Nodule number, chlorophyll content and available P in soil (after 30 days of sowing, i.e. at harvest).

For leaf area determination, the area of each expanded leaf was calculated as:

$\mathrm{K} x$ length $\mathrm{x}$ width

Where, $\mathrm{K}=0.75$ (Ruget et al., 1996).

Chlorophyll content: Chlorophyll content from leaf was measured by crushing the leaves in mortar pestle with $20 \mathrm{ml} \mathrm{80 \%} \mathrm{acetone.} \mathrm{The} \mathrm{extract} \mathrm{was} \mathrm{centrifuged}$ at $5000 \mathrm{rpm}$ for $5 \mathrm{~min}$. and supernatant was transferred to $100 \mathrm{ml}$ flask. Residue was ground with $20 \mathrm{ml} 80 \%$ acetone, centrifuged and supernatant was transferred to the same flask. The procedure was repeated until the residue became colourless. Volume was made upto $100 \mathrm{ml}$ with $80 \%$ acetone and absorbance was read at $645 \mathrm{~nm}$ and $663 \mathrm{~nm}$ against the solvent (80\% acetone) blank. The amoun of chlorophyll present in extract was calculated in terms of mg chlorophyll per $\mathrm{g}$ tissue using following formula:

$$
\text { mg chlorophyll a } / \mathrm{g} \text { tissue }=12.7\left(\mathrm{~A}_{663}\right)-2.59\left(\mathrm{~A}_{645}\right) \mathrm{X}-\underline{\mathrm{V}}
$$
$1000 \times \mathrm{W}$

2.

$$
\text { mg chlorophyll b } / \mathrm{g} \text { tissue }=22.9\left(\mathrm{~A}_{645}\right)-4.7\left(\mathrm{~A}_{663}\right) \underset{1000}{\mathrm{X}}-\frac{\mathrm{V}}{\mathrm{W}}
$$

Where,

$\mathrm{A}=$ Absorbance at specific wavelength,

$\mathrm{V}=$ Final volume of chlorophyll extract in $80 \%$ acetone,

$\mathrm{W}=$ Fresh weight of tissue extracted

\section{Testing Antifungal action of $B$. cepacia against $M$. phaseolina infestation in mung bean (in vitro studies)}

Seeds were surface sterilized as previously described and then coated with $1 \%$ CMC (Carboxymethyl Cellulose) mixed with fresh bacterial (B. cepacia, BAM12) culture filtrate and kept for drying for $1 \mathrm{hr}$ in an aseptic environment. Then seeds were wrapped with fungal mycelia and kept on a $3 \%$ water agar plate for germination at ambient temperature. Seeds treated with plain CMC and funga mycelia served as control. Seeds were observed after every $24 \mathrm{hrs}$ for symptoms of fungal infection till 8 days of treatment. Microscopic analysis of germinated seeds (seed, root, stem and leaves, wherever applicable) was also performed after every 48 hrs till 8 days to observe the effect of bacterial culture filtrate on growth and morphology of fungal mycelia.

\section{Heavy Metal Tolerance Assay}

The heavy metal tolerance capacity of $B$. cepacia was tested against 4 heavy metals, viz. arsenate, copper, lead and nickel in concentrations ranging from $0.5 \mathrm{mM}-25 \mathrm{mM}$ in LA plates. These metals were provided in the form of sodium arsenate, copper sulphate, lead acetate and nickel sulphate respectively. Same procedure was followed for checking the tolerance in liquid culture media (LB) also.

\section{RESULTS AND DISCUSSION}

Phosphate solubilization in Pikovskaya's agar plate and liquid medium: The organism produced pink colored zone of clearance against the yellow background in Pikovskaya's agar methyl red plates indicative of the acidic condition created due to secretion of organic acids by the bacteria during phosphate solubilization. The phosphate solubilization index was calculated during different days of incubation. It is inferred that the maximum increase in halo zone size occurred on the 2 nd and $9^{\text {th }}$ day of spot inoculation while there was regular increase in colony diameter right from the beginning till $10^{\text {th }}$ day.

The appraisal of the relative efficiency of the isolate in solubilizing phosphate was monitored quantitatively in Pikovskaya's broth medium, and the results have been depicted in Fig. 1. The maximum $\mathrm{P}$ solubilization happened within $24 \mathrm{hrs}$ of bacterial inoculation (149 ppm) that eventually led to sharp fall in $\mathrm{pH}$ value due to release of organic acids by the organism.

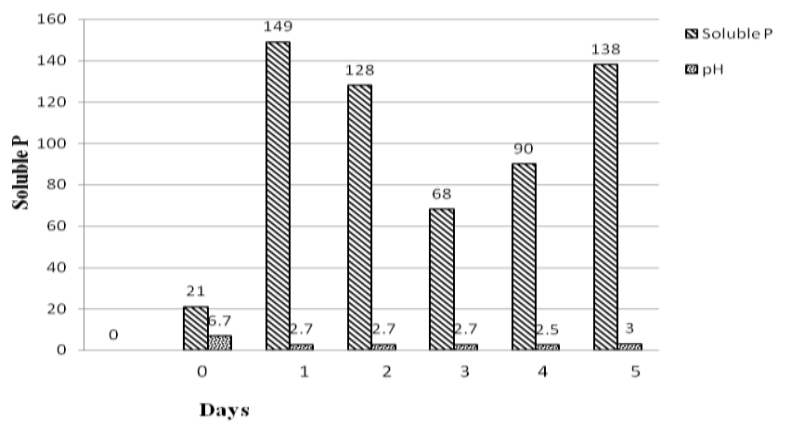

Figure 1 Tricalcium phosphate solubilization and subsequent $\mathrm{pH}$ drop in Pikovskaya broth by $P$. cepacia during different days of incubation (Soluble $\mathrm{P}$ has been expressed in ppm)

IAA production: The bacterial strain $P$. cepacia $\mathrm{BAM}-12$ was able to produce reasonably high amounts of IAA auxin i.e. $26.5 \mathrm{mg} / \mathrm{L}$ of the culture filtrate. Such a high amount of IAA production by the organism under investigation can help in the establishment and colonization of $P$. cepacia in plant rhizosphere which ultimately enhances the overall plant growth and plant biomass (Karthikeyan et al., 2009; Chandra et al., 2018).

Antibiotic sensitivity test: The bacterial isolate BAM-12 had shown sensitivity against Nalidixic acid, Tetracyclin and Erythromycin, whereas resistance against Streptomycin (10 mcg), Penicillin ( $2 \mathrm{mcg}$ ) and Ampicillin ( $2 \mathrm{mcg}$ ). The antibiotic resistance trait was exploited as a selectable marker in further plant growth related studies.

\section{Biocontrol activities}

Chitinase, lipase and Siderophore production: B. cepacia BAM-12 tested positive for chitinase and lipase enzymes as evident by the zone of clearance around bacterial colony in chitinase and tributyrene (Fig. 2C) agar plates respectively. A study conducted by Mota et al. (2017) has explained the role of lytic enzymes produced by microorganisms as one of the bases of bacterial antagonistic mechanisms. Formation of the yellow-orange halo zone on the CAS agar plate revealed the production of siderophore by the bacterial isolate (Fig. 2A and $2 \mathrm{~B}$ ). Percent rise in Siderophore production index was noted to be maximum within $48 \mathrm{hrs}$ after inoculation although a pattern of continuous rise was observed from $2^{\text {nd }}$ day onwards till $8^{\text {th }}$ day as depicted in Table 1 . 


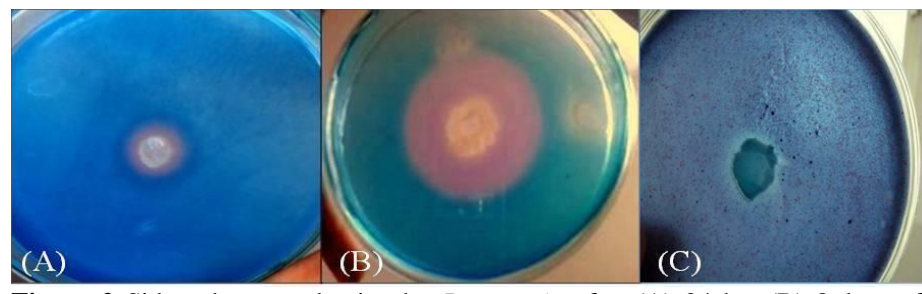

Figure 2 Siderophore production by B. cepacia after (A) 24 hrs (B) 8 days of inoculation. (C) Halo zone around B. cepacia colony on tributyrin agar plate after 24 hrs incubation

Table 1 Siderophore production index of B. cepacia during different days of incubation

\begin{tabular}{lccc}
\hline Days & $\begin{array}{c}\text { Halo zone } \\
(\mathrm{A})\end{array}$ & $\begin{array}{c}\text { Colony Diameter } \\
\text { (B) }\end{array}$ & $\begin{array}{c}\text { Siderophore Production } \\
\text { Index = A/B X 100 }\end{array}$ \\
\hline 1 & 1.53 & 1.22 & 125 \\
2 & 2.10 & 1.28 & 164 \\
3 & 2.5 & 1.3 & 192 \\
4 & 3.0 & 1.33 & 225 \\
5 & 3.2 & 1.40 & 228 \\
6 & 3.5 & 1.48 & 238 \\
7 & 3.6 & 1.50 & 240 \\
8 & 4.0 & 1.56 & 256 \\
\hline
\end{tabular}

Further characterization showed that siderophore produced by the organism was of catecholate type with quite substantial concentration of $18.05 \mathrm{mg} / \mathrm{L}$ higher than other reported Pseudomonas spp. like P. veronii (isolated from the rhizosphere of Arabidopsis thaliana) which produced $6.4 \mathrm{mg} / \mathrm{L}$ only (Grobelak \& Hiller 2017). Ferreira et al. (2019) have investigated the comparison of 5 bacterial strains producing siderophore under alkaline condition and found that Bacillus subtilis and Rhizobium radiobacter were catecholate producers. The obtained values indicate that the organism possesses high efficiency to chelate iron and eventually may be useful for acting against fungal phytopathogens.

HCN production by $B$. cepacia: $\mathrm{HCN}$ production by the PGPR strain is an additional advantage to its efficiency in defense during pathogen attack. In the current investigation $B$. cepacia was tested for $\mathrm{HCN}$ production by spectrophotometric and inverted plate methods. The organism showed pink color development on reaction with o-phosphoric acid confirming $\mathrm{HCN}$ production Further, growth of the pathogenic fungi $M$. phaseolina was suppressed substantially $(50 \%)$ in presence of $B$. cepacia in inverted plate method.

Antifungal activities in plate assay and liquid culture: Growth of $M$. phaseolina was inhibited by B. cepacia BAM-12 in plate assay as indicated by a clear zone around the bacterial colony (Fig. 3A). Of the 3 different amounts of bacterial culture $(10 \mu 1,25 \mu 1$ and $50 \mu 1)$ tested, even $10 \mu 1$ of culture was sufficient to suppress the fungal growth upto $30 \%$ after 7 days of incubation. During liquid culture studies in YEM broth, the culture filtrate of $B$. cepacia considerably inhibited the growth of $M$. phaseolina as compared to control. Development of heavy mycelial mat is quite apparent in the control flasks (Fig. 3B) compared to B. cepacia inoculated flasks (Fig. 3C) indicative of significant fungal growth inhibition. When the quantity of culture filtrate was raised in broth, a marked decline in fungal growth was recorded as shown in Table 2, at $10 \%$ culture filtrate had inhibited $82.8 \%$ fungal growth, $20 \%$ culture filtrate inhibited $84 \%$ and $30 \%$ culture filtrate inhibited $85.35 \%$ fungal growth. The observation clearly shows that $B$. cepacia strain possesses a strong antagonistic activity against $M$. phaseolina.

Microscopic studies demonstrating the effect of $B$. cepacia BAM-12 on fungal spore germination: The bacterial strains exhibit different mechanisms and pathways to stop the aggravation of fungal pathogens. In this view, the effect of B. cepacia culture filtrate on spore and mycelial growth of M. phaseolina was checked and observed under compound microscope. The normal growth of fungal spore and septate mycelium is apparent in the control set (Fig. 4A and 4D) without bacterial culture filtrate under 40X magnification, whereas swollen and broken mycelia (Fig. 4B) in the slide containing bacterial culture filtrate can be seen. Spore initially became constricted (Fig. 4 C) and eventually split and degraded in presence of bacterial culture filtrate, thus demonstrating intense antifungal potential of B. cepacia BAM-12.
Table 2 Antifungal activity of $B$. cepacia against $M$. phaseolina in liquid growth medium

\begin{tabular}{lccc}
\hline $\begin{array}{l}\text { Culture } \\
\text { filtrate }\end{array}$ & $\begin{array}{c}\text { Dry Weight of } M . \\
\text { phaseolina }(\mathrm{g}) \\
\text { Control }\end{array}$ & $\begin{array}{c}\text { Dry Weight of } M . \\
\text { phaseolina }(\mathrm{g}) \\
\text { Inoculated with } B . \\
\text { cepacia }\end{array}$ & $\begin{array}{c}\text { \% fungal } \\
\text { growth } \\
\text { inhibition }\end{array}$ \\
\hline $10 \%$ & $0.982+0.002$ & $0.145+0.001$ & 82 \\
$20 \%$ & $1.042+0.001$ & $0.16+0.002$ & 84 \\
$30 \%$ & $1.101+0.003$ & $0.172+0.002$ & 85.35 \\
\hline
\end{tabular}

(Values are mean \pm S.E. of three samples)

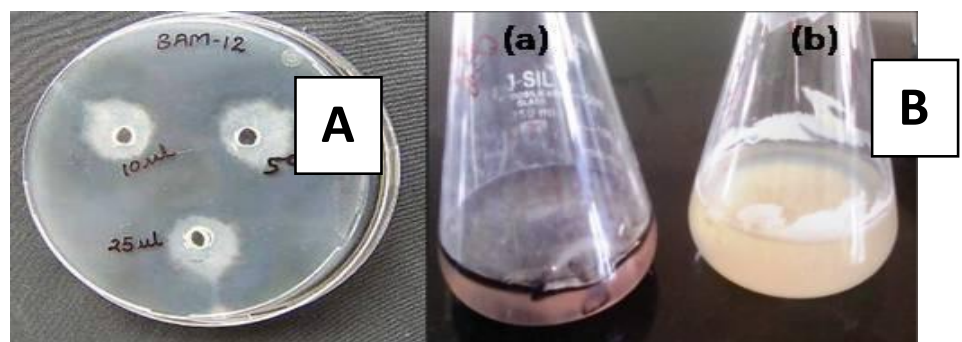

Figure 3 (A) Growth of M. pahseolina in plate assay. Growth of M. phaseolina in liquid culture (B) without bacterial inoculation (control), and (C) inoculated with $B$. cepacia

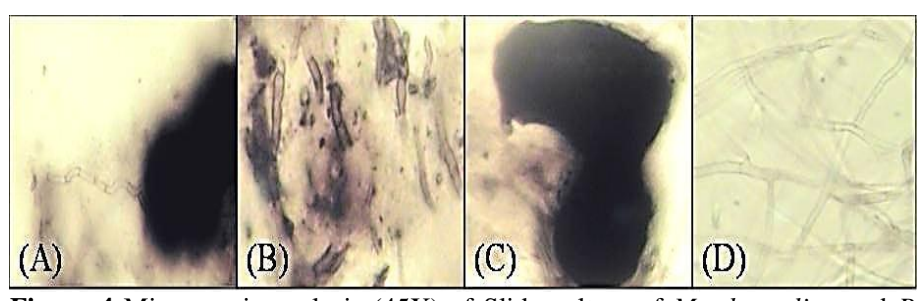

Figure 4 Microscopic analysis (45X) of Slide culture of M. phaseolina and $B$ cepacia after $24 \mathrm{hrs}$ of incubation. (A) Control slide showing normal spore of $M$. phaseolina without bacterial culture filtrate (B) Swollen and broken mycelia of $M$. phaseolina in slide treated with B. cepacia culture filtrate (C) constriction in spore as an effect of $B$. cepacia culture filtrate treatment $($ D) Normal $M$. phaseolina mycelia without bacterial culture filtrate in control slide

\section{In planta Studies}

It has been observed on several occasions that in vitro findings are not in coherence with the in vivo studies due to drastic differences in the environmental conditions (such as presence of soil and its intricate network of microflora and inorganic factors), therefore, it was quite relevant to carry out in planta studies in the present investigation. The strain $B$. cepacia BAM-12 has already proven its potential as a bio-inoculant in Mungbean plants in alkaline soils of Rajasthan, India (Jha et al., 2012). In order to broaden the applicability of this strain as inoculant further in terms of the environment and crop species, three agriculturally important crop plants (viz., maize, rice and mung bean) were selected for pot studies that was conducted in the soil collected from agricultural land of Anand District (Karamsad village) in Gujarat, India. During plant growth evaluation, some morphological differences like the number of leaves and shoot length were apparent among the treatments within a few days of seed sowing, and therefore, were compared only after 15 days of seed sowing whereas the additional growth parameters were assessed after 30 days of seed sowing alongwith these parameters.

Soil testing indicated that the $\mathrm{pH}$ of the soil was near neutral (i.e. 7.3) and moisture content was found to be $15.18 \%$.

Percent germination: The percent germination was compared after 5 days of PSB inoculation and it was found that the values were similar in control and PSB treated pots for rice and mungbean $(75 \%)$, except the maize plants where the value of percent seed germination in treated pots was just double the value of control pots. It proves that the inoculation improved the seed germination efficiency in maize plants.

\section{Plant growth assessment at 15 days after seed sowing (DAS)}

Inoculation of seeds with bacterial strain $B$. cepacia BAM-12 significantly improved the overall plant growth in comparison to the control in all the three crop species.

Number of leaves/plant: PSB inoculation resulted in the increased number of leaves in rice and mung bean plants but the maize plants remained unaffected at 15 DAS.

Shoot length: Increase in shoot length values was most striking in case of $B$ cepacia treated rice and mung bean plants, where more than $100 \%$ increase was 
seen in comparison to the control plants. In maize plants also notable rise (approx. 17\%) in shoot length was observed in treated plants as compared to control plants. Rise in shoot length might have happened due to the combined effect of $\mathrm{P}$ solubilization and the production of growth-promoting substances by B. cepacia BAM -12 that eventually helped in stem expansion process (Jha et al. 2012; Chandra et al., 2018).

\section{Plant growth parameters at harvest (30 DAS)}

As evident from Fig. 5 and 6, inoculation of seeds with bacterial strain B. cepacia BAM-12 significantly improved the overall plant growth in comparison to the control in all the three crop species.

Plant height: Plant height is indicative of its growth and eventually determines the crop yield. Seed treatment with $B$. cepacia increased overall height of rice plants by $38.70 \%$ and of maize plants by $19.04 \%$ and significantly highest in mung bean plants by $58.75 \%$ as compared to un-inoculated control plants. The increase may be due to the production of growth promoting substances by the inoculated bacteria that carry out an important role in the stem expansion process, as discovered by Bonner (1961) and Weaver (1980). The highest growth augmentation in mungbean ascertains greater competence of PSB strain to its native crop species than others.

Plant Fresh weight and dry weight (root and shoot): As shown in Table 3 there is a remarkable increase in fresh and dry weight of treated plants over uninoculated control. Such increase in dry weight may confer advantages to the host system with respect to its health and growth
Leaf number and leaf area: The numbers of leaves were recorded more in the treated plants over control except in the maize plant, where the difference was not remarkable (Fig. 5). This parameter was again remarkable in the mungbean after 15 and 30 days in comparison to other plants, which again proves that it was due to the fact that mungbean is the native plant for the bacterial strain. As shown in Table 3 leaf area is denoted higher in rice and mungbean plants as compared to un-inoculated control plants ( $20 \%$ and $30 \%$ respectively), with only little increase in maize plants (i.e. $2 \%$ ).

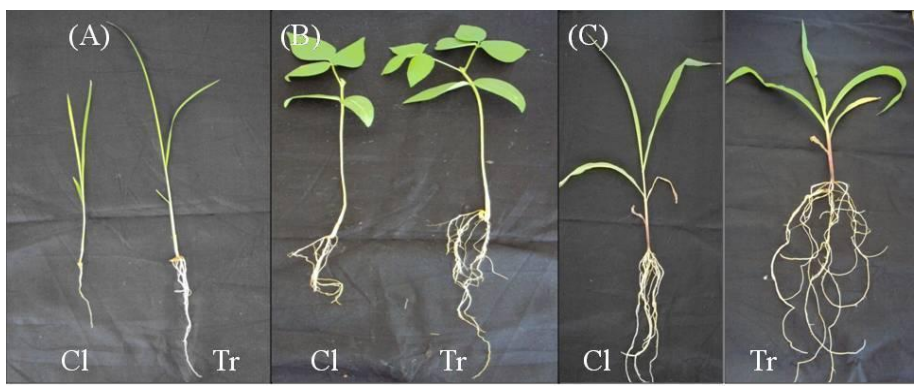

Figure 5 Growth of Rice (A), Mungbean (B) and Maize (C) after 30 days, where control plant is denoted as $\mathrm{Cl}$ and treated as $\mathrm{Tr}$

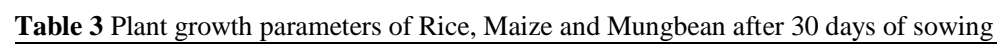

\begin{tabular}{lccccc}
\hline Parameters & \multicolumn{2}{c}{ Rice } & \multicolumn{2}{c}{ Maize } & \multicolumn{2}{c}{ Mung bean } \\
& Control & Treated & Control & Treated & Control \\
\hline $\begin{array}{l}\text { Plant Fresh weight } \\
\text { (gm)/plant }\end{array}$ & $0.092+0.002$ & $0.149+0.006$ & $2.17+0.004$ & $2.357+0.001$ & $0.679+0.008$ \\
$\begin{array}{l}\text { Plant Dry weight } \\
(\text { gm)/plant }\end{array}$ & $0.033+0.001$ & $0.09+0.003$ & $0.467+0.005$ & $0.889+0.003$ & $0.286+0.002$ \\
$\begin{array}{l}\text { Leaf Area } \\
(\mathrm{cm} 2)\end{array}$ & $1.63+0.007$ & $1.97 \pm 0.002$ & $26.24 \underline{+1.20}$ & $26.83 \pm 1.34$ & $0.815+0.003$ \\
\hline
\end{tabular}

(Values are mean \pm S.E. of four samples)

Table 4 Chlorophyll content in Rice, Maize and Mungbean plants after 30 days of sowing

\begin{tabular}{lcccccc}
\hline $\begin{array}{l}\text { Chlorophyll } \\
\text { (mg/g tissue) }\end{array}$ & \multicolumn{2}{c}{ Rice } & \multicolumn{3}{c}{ Maize } & \multicolumn{3}{c}{ Mung bean } \\
\hline Chl a & Control & Treated & Control & Treated & Control \\
Chl b & $1.058+0.002$ & $1.505+0.003$ & $0.664+0.003$ & $1.026+0.003$ & $1.094+0.002$ \\
Total Chl (a+b) & $0.612+0.001$ & $0.672+0.003$ & $0.381+0.002$ & $0.368+0.002$ & $0.432+0.003$ & $0.578+0.003$ \\
\hline
\end{tabular}

(Values are mean \pm S.E. of four samples)

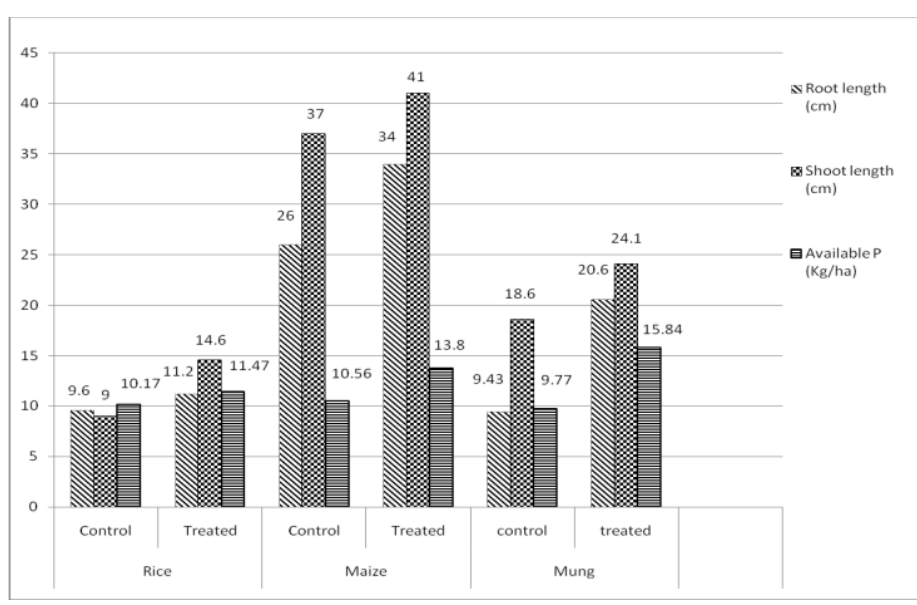

Figure 6 Root length, shoot length and soil available phosphorus (P) concentration of rice, maize and mung bean plants after 30 DAS (days after sowing) as influenced by $B$. cepacia inoculation

Root branching: Root branching and root biomass significantly increased in all treated plants as compared to un-inoculated control (Fig. 5) and hence, the better developed root branching system may increase nutrient uptake by plants due to increased surface area. Indole-3-acetic acid is a phytohormone which is known to be involved in root initiation, cell division, and cell enlargement (Barazani \& Friedman, 1999) and significant IAA secretion by the isolate corroborates the observed effect.
Nodule number in leguminous plant, mung bean: The nodule number in the bacteria treated mung bean plant was noted to be higher ( 8 in number) than that of control plants ( 3 in number) showing $\sim 167 \%$ increase in nodulation.

Chlorophyll Content: The estimated chlorophyll content has been shown in Table 4. The values of total chlorophyll content were recorded again higher in treated plants as compared to control with highest increment in rice plants. Also the treated plants were optimally green in color in comparison to the untreated plants. It is possible that PSB inoculated plants may have more number of chloroplasts per cell, hence more chlorophyll, ultimately affecting the photosynthetic yield. Wang et al. (2004) found a positive relationship between chloroplast number and photosynthesis in Nicotiana sylvestris.

Deficiency symptoms in plants: In maize control plants several deficiency symptoms associated with the inadequacy of the macroelements like nitrogen, phosphorus and potassium were observed. The symptoms were pale green colored leaves and weak stem; leaves with forward roll and scorched margins and defoliation of oldest leaves; short internodal length relatively longer leaves, marginal and tip browning of leaves. Such deficiency symptoms were insignificant in B. cepacia treated plants.

Rhizosphere bacterial Population: The introduced PSB were found to establish themselves well in the plant rhizosphere as shown by the cell count taken after 30 days of sowing (Table 5). It is evident from the results that in all the bacterial inoculated treatments, the population increased towards the maturation of the crop. The microbial population of soil was found to be higher in case of treated plants as compared to control showing occurrence of microbes in soil with inoculation of B. cepacia. 
Table 5 Rhizosphere bacterial population of soil (CFU/ml) after 30 days of sowing.

*Initial rhizosphere bacterial population of soil at start of the experiment: $2.4 \mathrm{x}$ $10^{6} \mathrm{CFU} / \mathrm{ml}$

\begin{tabular}{cccccc}
\hline \multicolumn{2}{c}{ Rice } & \multicolumn{2}{c}{ Maize } & \multicolumn{2}{c}{ Mung bean } \\
Control & Treated & Control & Treated & Control & Treated \\
\hline $2.6 \times 10^{6}$ & $3.1 \times 10^{6}$ & $2.45 \times 10^{6}$ & $2.95 \times 10^{6}$ & $2.5 \times 10^{6}$ & $3.3 \times 10^{6}$ \\
\hline
\end{tabular}

Higher number of PSB recorded after harvesting of mung bean plants at 30 days may be ascribed to the reason that bacteria took time to establish themselves in the rhizosphere and this time period varies from bacterium to bacterium Moreover, establishment of a threshold population of viable inoculants is an important prerequisite for plant-microbe interactions like growth enhancement and biocontrol by bacteria. The results are in close conformity with those reported by Raja et al. (2002) who reported the establishment of bacterial populations in wheat inoculated with phosphobacteria.

Available Phosphorus: The values of available phosphorus estimated have been shown in Fig. 6 with significant higher values in treated soil as compared to control. Phosphorous is a frequently limiting macronutrient next only to nitrogen for plant growth and makes about $0.2 \%$ of plant dry weight (Schachtman et al., 1998). The increment in available phosphorus shows capability of $P$. cepacia to bio-ameliorate the soil Pi by converting them into soluble orthophosphates that can be taken up by the plants. Highest increase was found in mung bean plants as compared to maize and rice.

Testing Antifungal action of $B$. cepacia against $M$. phaseolina infestation in mung bean (in planta studies)

The percent seed germination was found to be $17.6 \%$ in the $M$. phaseolina treated control against $85 \%$ in the PSB treated, Macrophomina challenged seeds after 8 days of growth under ambient conditions (Fig. 7). Among these germinated seeds only $25 \%$ of control (M. phaseolina treated) seeds had shown little rooting compared to profuse rooting and appearance of two leaf stage in $70 \%$ mung seeds (fungi challenged and PSB treated) after 8 days of growth.

The overall plant height in the control plant (without any treatment) was noted to be $15 \mathrm{~cm}$ while $6 \mathrm{~cm}$ in Macrophomina challenged control plants. On the contrary the treated seeds (with PSB culture and Macrophomina) showed $20 \mathrm{~cm}$ overall plant height (Fig. 9). This clearly demonstrates the growth stimulating and biocontrol potential of $B$. cepacia inoculation on the seeds leading to increased plant height and growth.

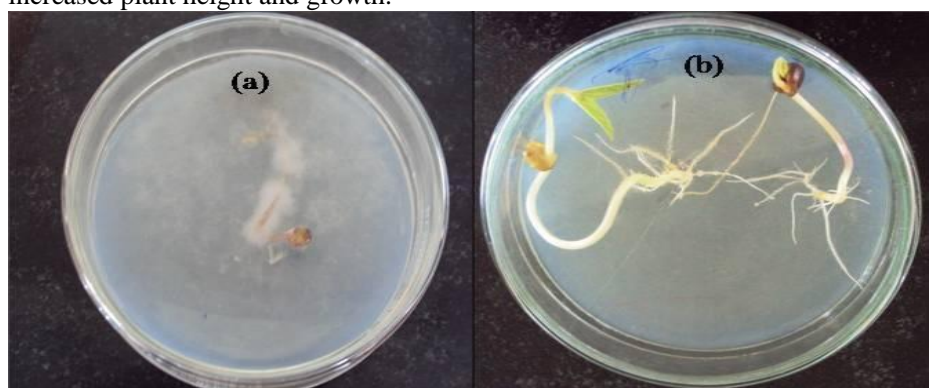

Figure 7 In planta antifungal activity against phytopathogen, M. phaseolina infestation in mung bean; (a) M. phaseolina treated Mungbean after 8 days (b) $M$. phaseolina and B. cepacia treated mungbean after 8 days

Microscopic Analysis: Microscopic analysis (400x magnifications in a compound binocular microscope) of root, stem and leaf sections of Mungbean plants revealed that the disease progression happened in pathogen challenged plants over the period of 8 days of growth. This was confirmed by the presence of disorganized, ruptured and damaged groups of cortical and endodermal cells and change in cell morphology in these sections. Blackening of the root started on the 2nd day of Macrophomina infection and advanced till the 8th day making the seed as a dead mass. On contrary the treatment of mung seeds with BAM-12 highly reduced the impact of Macrophomina attack observed as negligible blackening in roots, healthier than control plants, shoot section having intact cells without any damage.

\section{Heavy metal tolerance by B. cepacia BAM-12}

Agricultural soils in many parts of Asia are being contaminated by industrial wastes containing heavy metals such as arsenate, copper, nickel and lead that may have a highly deleterious effect on the microflora of soil. Thus, the efficacy of $B$. cepacia was tested for bioremediation of these heavy metals in different concentrations ranging from $0.5 \mathrm{mM}$ to $25 \mathrm{mM}$ and had shown efficiency to tolerate different concentrations for each heavy metal, i.e. $1.5 \mathrm{mM}$ arsenate, 25 $\mathrm{mM}$ copper, $10 \mathrm{mM}$ nickel and $25 \mathrm{mM}$ lead respectively. Its tolerance upto 25 $\mathrm{mM}$ is indicative of its potential to be used in heavy metal remediation at contaminated sites, especially the agricultural fields. Studies on heavy metal tolerance by bacterial strains and its role in bioremediation (Jain et al., 2012, 2014) have revealed that the remodulation of the central carbon metabolic pathway takes place in metal contaminated environments. Additionally, $B$ cepacia BAM-12 is also an efficient catecholate producer which might have accentuated the bioremediation process by reducing the heavy metals toxicity (Grobelak \& Hiller, 2017).

\section{CONCLUSIONS}

In the present study a Mungbean bacterial isolate B. cepacia BAM-12 from Rajasthan agricultural field soil has demonstrated its efficacy in Gujarat agricultural field soil in terms of improving the growth of 3 highly important crops viz., Mungbean, maize and rice. Such type of crop growth improvement may be attributed to the multifaceted activities demonstrated by this isolate like direct growth enhancement (high amount of IAA production, P-solubilization), and biocontrol ability (catecholate production, chitinase and lipase activity, HCN production). Additionally the isolate has also a heavy metal tolerance trait which may be exploited for crop production in copper and lead contaminated sites. It is presumed that indigenous strains are mostly effective with indigenous plants and soil, but the isolate used in this study has demonstrated its potential in various crop species and different soil. Further, alongwith some other robust PGPRs it may be tested with other crop species at multilocational fields for expanding its applications.

\section{Conflict of interest: The authors have no conflict of interest.}

Acknowledgements: We are thankful to Charutar Vidya Mandal (CVM), Vallabh Vidyanagar, Anand, India for the financial assistance and CHARUSAT University, Changa, for necessary support.

ORCID: Anamika Jha https://orcid.org/0000-0002-2665-1982

\section{REFERENCES}

Allen, S.C. 1989. Chemical analysis of ecological materials (ed. Steward SE). Blackman Scientific, Oxford, pp. 368.

Arnow, L.E. 1937. Colorimetric estimation of the components of 3,4-dihydroxy phenylalanine tyrosine mixtures. Journal of Biological Chemistry, 118:531-537. https://doi.org/10.1016/S0021-9258(18)74509-2

Atkin, C.L., Neilands, J.B. and Phaff, H.J. 1970. Rhodotorulic acid from species of Leucosporidium, Rhodosporidium, Rhodotorula, Sporidiobolum and Sporobol omyces and a new alanine-containing ferrichrome from Cryptococcus melibiosum. Journal of Bacteriology, 103:722-733. https://doi.org/ 10.1128/JB.103.3.722-733.1970

Barazani, O. and Friedman, J. 1999. Is IAA the major root growth factor secreted from plant-growth-mediating bacteria? Journal of Chemistry and Ecology, 25:2397-2406. https://doi.org/10.1023/A:1020890311499

Bonner, J. 1961. On the mechanism of auxin-induced growth. In: Plant growth regulation. Fourth international conference. The lowa state university press, Aims, lowa, USA, pp. 307.

Bric, J.M., Bostock, R.M. and Silverstone, S.E. 1991. Rapid in situ assay for indole acetic acid production by bacteria immobilization on a nitrocellulose membrane. Applied Environmental Microbiology, 57:535-538. https://doi.org/10.1128/aem.57.2.535-538.1991

Chandra, S., Askari, K. and Kumari, M. 2018. Optimization of indole acetic acid production by isolated bacteria from Stevia rebaudiana rhizosphere and its effects on plant growth. Journal of Genetic Engineering and Biotechnology, 16:581-586. https://doi.org/10.1016/j.jgeb.2018.09.001

Ferreira, C.M.H., Boas, Â.V., Sousa, C.A., Soares, H.M.V.M. and Soares, E.V. 2019. Comparison of five bacterial strains producing siderophores with ability to chelate iron under alkaline conditions. AMB Express, 9:78 https://doi.org/10.1186/s13568-019-0796-3

Grobelak, A. and Hiller, J. 2017. Bacterial siderophores promote plant growth screening of catechol and hydroxamate siderophores. International journal of phytoremediation,

https://doi.org/10.1080/15226514.2017.1290581

Jain, R., Jha, S., Adhikary, H., Jha, A. and Kumar, G.N. 2012. Remodulation of central carbon metabolic pathway in response to arsenite exposure in Rhodococcus sp. strain NAU-1. Journal of Microbial Biotechnology, 5:764-772. https://doi.org/10.1111/j.1751-7915.2012.00368.x

Jain, R., Jha, S., Adhikary, H., Kumar, P., Parekh, V., Jha, A., Mahatma, M.K. and Kumar, G.N. 2014. Isolation and molecular characterization of Arsenite tolerant Alishewanella sp. GIDC-5 originated from industrial effluents. Geomicrobiology, 31:82-90. https://doi.org/10.1080/01490451.2013.811317

Jha, A., Saxena, J. and Sharma, V. 2013. An Investigation on Phosphate Solubilization Potential of Agricultural Soil Bacteria as Affected by Differen Phosphorus Sources, Temperature, Salt and $\mathrm{pH}$. Communications in soil science and plant analysis, 44:2443-2458. https://doi.org/10.1080/00103624.2013.803557 
Jha, A., Saxena, J. and Sharma, V. 2011. Phosphate solubilizers as biofertilizer: A boon to agriculture. Lambert Publishing, Germany, pp.1-240. https://www.lappublishing.com/catalog/details/store/gb/book/978-3-8465-4503-4/phosphatesolubilizers-as-biofertilizer

Jha, A., Sharma, D. and Saxena, J. 2012. Effect of single and dual phosphate solubilizing bacterial strain inoculations on overall growth of mungbean plants. Archives of agronomy and soil science, 58:967-981. https://doi.org/10.1080/03650340.2011.561835

Karthikeyan, B., Jaleel, A. and Azooz, M.M. 2009. Individual and Combined Effects of Azospirillum brasilense and Pseudomonas fluorescens on Biomass Yield and Ajmalicine Production in Catharanthus roseus. Academic Journal of Plant Sciences, 2: 69-73.

Kumar, V. and Narula, N. 1999. Solubilization of inorganic phosphates and growth emergence of wheat as affected by Azotobacter chroococcum mutants Biology and fertility of soils, 28:301-305. https://doi.org/10.1007/s003740050497 Mota, M.S., Gomes, C.B., Souza Júnior, I.T. and Moura, A.B. 2017. Bacteria selection for biological control of plant disease: criterion determination and validation. Brazilian Journal of Microbiology, 48(1):62-70. https://doi.org/10.1016/j.bjm.2016.09.003

Nezarat, S. and Gholami, A. 2009. Screening plant growth promoting rhizobacteria for improving seed germination, seedling growth and yield of maize. Pakistan Journal of Biological Sciences, 12:26-32. https://doi.org/10.3923/pjbs.2009.26.32

Nies, D.H. 1999. Microbial heavy-metal resistance. Applied Microbiology and Biotechnology, 51: 730-750. https://doi.org/10.1007/s002530051457

Olsen, S.R. and Sommers, L.E. 1982. Phosphorus In: Page AL Miller RH Keeney DR (Eds.). Methods of Soil Analysis. Part 2. 2nd ed. ASA and SSSA Publisher, Madison, pp. 403-430. https://doi.org/10.2134/agronmonogr9.2.2ed.c24

Parikh, K. and Jha, A. 2012. Biocontrol features in an indigenous bacterial strain isolated from agricultural soil of Gujarat, India. Journal of soil science and plant nutrition, 12:249-256. https://doi.org/10.4067/s0718-95162012000200004

Raja, A.K., Shah, K.H., Aslam, M. and Memon, M.Y. 2002. Response of phosphobacterial and mycorrhizal inoculation in wheat. Asian Journal of Plant Science, 1:322-323. https://doi.org/10.3923/ajps.2002.322.323

Ruget, F., Bonhomme, R. and Chartier, N. 1996. Estimation simple de la surface foliaire de plantes de maiis en croissance. Agronomie, 16:553-562. https://doi.org/10.1051/agro:19960903

Schachtman, D.P., Reid, R.J. and Ayling, S.M. 1998. Phosphate uptake by plants from soil to cell. Plant Physiology, 116:447-453. https://doi.org/10.1104/pp.116.2.447

Shrivastava, R. and Shalini. 2009. Antifungal activity of Pseudomonas fluorescens against pathogenic fungi. The internet journal of Microbiology, 7(2). https://doi.org/10.5580/1e69

Slama, M.I., Omar, A.E.K., Bassiony, S.S. and Ghoneem, G.M. 2019. Effect of compost and natural rocks as partial substitutes for NPK mineral fertilizers on yield and fruit quality of flame seedless grapewinegrown in two different locations of Egypt. Spanish Journal of Agricultural Research, 17(3):1-10 https://doi.org/10.5424/sjar/2019172-14355

Thakuria, D., Talukdar, N.C., Goswami, C., Hazarika, S., Boro, R.C. and Khan M.R. 2004. Characterization and screening of bacteria from rhizosphere of rice grown in acidic soils of Assam. Current Science, 86:978-98.

Vessey, J.K. 2003. Plant growth promoting rhizobacteria as biofertilizers. Plant and Soil, 255: 571-586. https://doi.org/10.1023/a:1026037216893

Wang, X., Anderson, O.R. and Griffin, K.L, 2004. Chloroplast numbers, mitochondrion numbers and carbon assimilation physiology of Nicotiana sylvestris as affected by $\mathrm{CO}_{2}$ concentration. Journal of Environment and Experimental Botany, 51:21-31. https://doi.org/10.1016/s0098-8472(03)00057-1

Weaver, R.J. 1980. Reguladores del crecimiento de las plantas en la agricultura (ed. P. Trillas). Mexico, pp. 91-113 